\title{
Evaluation of Mechanical, Microstructures and Wear Behaviours of Aluminium Alloy Reinforced with Mussel Shell Powder for Automobile Applications
}

\author{
Idawu Yakubu Suleiman ${ }^{1}$ - Auwal Kasim ${ }^{2}$ - Abdullahi Tanko Mohammed ${ }^{3}$ - Munir Zubairu Sirajo ${ }^{4}$ \\ 1University of Nigeria, Department of Metallurgical and Materials Engineering, Nigeria \\ ${ }^{2}$ Ahmadu Bello University, Department of Metallurgical and Materials Engineering, Nigeria \\ ${ }^{3}$ Waziri Umaru Federal Polytechnic, Department of Mechanical Engineering, Nigeria \\ ${ }^{4}$ Petroleum Technology Development Fund, Abuja, Nigeria
}

This paper aims to investigate the mechanical (tensile, hardness, impact, elongation), microstructure and wear behaviours of aluminium alloy reinforced with mussel shell powder (MSP) at different weight percentages (0 wt. \% to 15 wt. \%) at 3 wt. \% interval. The mussel shell powder was characterized by X-ray fluorescence (XRF). The matrix and the composites' morphology were studied using a scanning electron microscope attached with energy dispersive spectroscopy for the distribution of mussel shell powder particles within the matrix. The wear behaviour of the alloy and composites produced at various reinforcements were carried out using a Taber abrasion wear-testing machine. The XRF showed the compositions of MSP to contain calcium oxide (95.70\%), silica (0.83\%) and others. Mechanical properties showed that tensile values increase with increases in MSP, hardness value increases from 6 wt. \% to 15 wt. \% of MSP. The impact energy decreased from $42.6 \mathrm{~J}$ at 3 wt. \% to $22.6 \mathrm{~J}$ at 15 wt. \%; the percentage elongation also decreased from $37.4 \%$ at 3 wt. \% to 20.5 \% at 15 wt. \% MSP, respectively. The bending stress results increase with increases in the percentage of reinforcement. The morphologies revealed that uniform distribution of MSP within the matrix resulted to improvement in mechanical properties. The wear resistance of the composites increases with increase in the applied load and decreases with increases in the weight percentage of MSP and can be used in the production of brake pads and insulators in the automobile industry.

Keyword: aluminium alloy, composites, mussel shell powder, mechanical properties, microstructures, wear behaviour

Highlights

- The use of aquaculture (mussel) shell waste material as reinforcement in aluminium metal composites has proved to be a cost-effective, environmentally friendly and good substitute to imported synthetic reinforcements, which can be utilized in the automobile industry.

- The XRF analysis of mussel shell powder contains ceramic materials, such as calcium oxide (CaO), silica $\left(\mathrm{SiO}_{2}\right)$, iron oxide $\left(\mathrm{Fe}_{2} \mathrm{O}_{3}\right)$, magnesium oxide ( $\left.\mathrm{MgO}\right)$, aluminium oxide $\left(\mathrm{Al}_{2} \mathrm{O}_{3}\right)$, and strontium $(\mathrm{SrO})$, which were uniformly distributed within the composites and contributed immensely to the properties investigated.

- The wear rate was significantly lower in the aluminium metal composites produced, and varies with normal load, and the cumulative volume loss increases with increasing applied normal load. The reinforcement of mussel shell powder particles in the Al-Si-Mg alloy matrix decreased the wear resistance of the composites produced.

- The mechanical results obtained showed that the composite produced can be tailored toward achieving the desired or unique properties for particular applications in the automobile or aerospace industries.

\section{INTRODUCTION}

The growth of world's population and increase of living standard due to technological development have increased the quantity of waste materials generated through industrial, mining and agricultural activities substantially. The waste materials are becoming major concern to both environmentalists and human beings globally [1]. Utilization of waste materials could reduce contamination and free up spaces for disposal or recycling of waste materials by converting it into useful material for applications in aerospace and automobile/construction industries could save the world from natural disasters as being observed [2].
Aluminium matrix composites (AMCs) are presently produced by employing several conventional and patented methods. The properties of AMCs are governed by the processing method. A liquid route, such as casting, is relatively simple and economical, but the limited wettability of reinforcement in molten aluminium limits its usage. The economy, simplicity and ability to produce large and intricate parts are the key parameters that make stir casting the most preferred method for producing AMCs. The limitation of stir casting is the wettability between the molten aluminium matrix and the ceramic particle. AMCs produced through conventional casting offer difficulties in the even mixing of the reinforcement in main matrix [2]. The difference in densities of the 
base matrix and reinforcement hinders the distribution of reinforcement in the main matrix and promotes the formation of agglomerates or clusters. This can be avoided by employing a stirrer in the molten mixture so that the difference in energies may be checked. The stirring of the molten mixture before pouring into the mould cavity promotes the uniform distribution of reinforcement in the aluminium matrix, induces vortex formation, and the reinforced particles are mixed at the side of the vortex [3].

The reinforced materials with ashes or powders had produced materials that are quite friendly with environmental and cost-effective benefits [3]. Aluminium-based Metal Matrix Composites (MMCs) have received increasing attention in recent decades as engineering materials, and the introduction of ceramic material into a metal matrix produces a composite material that resulted in an attractive combination of physical, chemical, and mechanical properties that cannot be obtained with the aluminium alloys alone [4].

Different reinforcements such as aluminium oxide $\left(\mathrm{Al}_{2} \mathrm{O}_{3}\right)$, silicon carbide $(\mathrm{SiC})$, titanium carbide $(\mathrm{TiC})$, tungsten $(\mathrm{W})$, calcium oxide $(\mathrm{CaO})$, silica $\left(\mathrm{SiO}_{2}\right)$ etc have been used to enhance aluminium composite properties. Studies had also shown that hardness, toughness, tensile and wear rate behaviours were enhanced [5]. These unnatural reinforcers frequently used were difficult to obtain in Nigeria and the importation of such materials are at high cost and time constraint, which may impede the production of the composites. An alternative to these reinforcements in developing countries is to explore agricultural and aquaculture wastes, either in the form of ashes or powder. The wastes of bagasse [6], melon shell ash studied [7], periwinkle shell powder was used [8], and oyster shells, among others, for the development of AMCs had been investigated [9]. The results had also shown that waste ashes and powder generated contain high percentages of refractory materials, such as alumina $\left(\mathrm{Al}_{2} \mathrm{O}_{3}\right)$, silica $\left(\mathrm{SiO}_{2}\right)$, hematite $\left(\mathrm{Fe}_{2} \mathrm{O}_{3}\right)$, carbonate $\left(\mathrm{CaCO}_{3}\right)$ and calcium $(\mathrm{Ca})$, among others, which can be explored for the production of composite

Mussel shell is an aquaculture waste generated across the southern part of Nigeria and poses a serious threat to both the environment and human lives. In order to relieve this region of this threat, the mussel shells were collected, subjected to treatments, and convert to powder under strict conditions. From the above aforementioned, the present paper, therefore, investigates the use of aquaculture-mussel shell powder (MSP) of particle size $100 \mu \mathrm{m}$ by dispersing it into an alloy via liquid metallurgy to obtain composite. Mussel powder was varied from 0 wt. $\%$ to 15 wt. $\%$ at 3 wt. $\%$ interval. The chemical analysis of mussel powder was also carried out, mechanical, microstructure and the wear rate of the matrix and composites were carried out simultaneously.

\section{EXPERIMENTAL}

\subsection{Material Preparation}

Mussel shell powder was prepared by cleaning, washing, drying, grinding and sieving it to obtain a uniform size. The sieving was done at the Department of Agriculture and Bio-resources Engineering, University of Nigeria, Nsukka with an electricpowered sieving machine. A sieve of $100 \mu \mathrm{m}$ was used to sieve the mussel powder to uniform sizes. Fig. la show the mussel shell collection while fig. $1 \mathrm{~b}$ also showed the MSP of particle size $100 \mu \mathrm{m}$ produced respectively. The chemical compositions of the MSP are presented in Table 1.

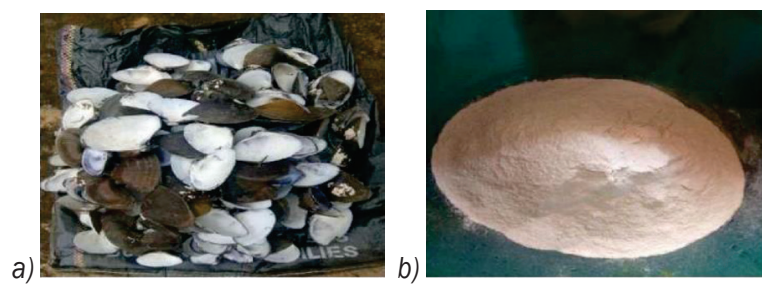

Fig. 1. a) Mussel shell collections, and b) mussel shell of particle size of $100 \mu \mathrm{m}$

Table 1. The mussel powder analysis

\begin{tabular}{cc}
\hline Compounds & Mussel shell powder [\%] \\
\hline $\mathrm{CaO}$ & 95.70 \\
\hline $\mathrm{K}_{2} \mathrm{O}$ & 0.35 \\
\hline $\mathrm{SiO}_{2}$ & 0.83 \\
\hline $\mathrm{SrO}$ & 0.26 \\
\hline $\mathrm{Fe}_{2} \mathrm{O}_{3}$ & 0.67 \\
\hline $\mathrm{SO}_{3}$ & 0.46 \\
\hline $\mathrm{MgO}$ & 0.48 \\
\hline $\mathrm{Al}_{2} \mathrm{O}_{3}$ & 0.46 \\
\hline
\end{tabular}

\subsection{Production of Al-Mg-Si/Mussel shell powder particulate composites}

The present study utilized aluminium alloy and mussel shell powder with a particle size of $100 \mu \mathrm{m}$ as base matrix and reinforcement, respectively. The chemical composition of the alloy is presented in Table 2. The amounts of mussel shell powder (MSP) used as reinforcers were determined using charge 
calculations presented in Table 3. The aluminium alloy was superheated to $800{ }^{\circ} \mathrm{C}$ after being charged into a crucible furnace. The stainless-steel stirrer was used to stir the molten alloy/composites manually. The reinforcement particles, MSP, were preheated to $200{ }^{\circ} \mathrm{C}$ for 30 minutes. After preheating, MSP particles were consolidated into the melt to exclude moisture. To reduce the porosity, the addition of the degassing tablet was added after the alloy/composites were completely melted. The wettability was enriched by the composition of magnesium in the melt. This magnesium improves the wettability between the matrix alloy, reinforcement thus, 3 wt. $\%$ to 15 wt. $\%$ at $3 \mathrm{wt} . \%$ interval by equal MSP proportions used. Preheated moulds were set before casting the alloy and the composite of $30 \mathrm{~mm}$ by $100 \mathrm{~mm}$, respectively. Chemical analyses were performed on the alloy and the composite. Fig. 2 shows the preparation, equipment and cast products (alloy/composite) for this research.

Table 2. Al-Mg-Si alloy analysis

\begin{tabular}{lccccccc}
\hline Compositions & $\mathrm{Mg}$ & $\mathrm{Si}$ & $\mathrm{Fe}$ & $\mathrm{Mn}$ & $\mathrm{Cr}$ & $\mathrm{Cu}$ & $\mathrm{Al}$ \\
\hline $\begin{array}{l}\text { Weight percent } \\
\text { [wt. \%] }\end{array}$ & 1.0 & .60 & .01 & .02 & .01 & .03 & $\mathrm{Bal}$. \\
\hline
\end{tabular}

Table 3. Summary of charge calculations in weight percent [wt. \%]

\begin{tabular}{lcccccc}
\hline S/No. & $\begin{array}{c}0 \text { wt.\% } \\
\text { MSP }\end{array}$ & $\begin{array}{c}3 \text { wt.\% } \\
\text { MSP }\end{array}$ & $\begin{array}{c}6 \text { wt.\% } \\
\text { MSP }\end{array}$ & $\begin{array}{c}\text { 9 wt.\% } \\
\text { MSP }\end{array}$ & $\begin{array}{c}12 \text { wt.\% } \\
\text { MSP }\end{array}$ & $\begin{array}{c}15 \text { wt.\% } \\
\text { MSP }\end{array}$ \\
\hline [MSP] & 0 & 3 & 6 & 9 & 12 & 15 \\
\hline Silicon (Si) & 0.600 & 0.600 & 0.600 & 0.600 & 0.600 & 0.600 \\
\hline Magnesium & 1.000 & 1.000 & 1.000 & 1.000 & 1.000 & 1.000 \\
\hline Aluminium & 98.400 & 95.400 & 92.400 & 89.400 & 86.400 & 83.400 \\
\hline Total & 100 & 100 & 100 & 100 & 100 & 100 \\
\hline
\end{tabular}
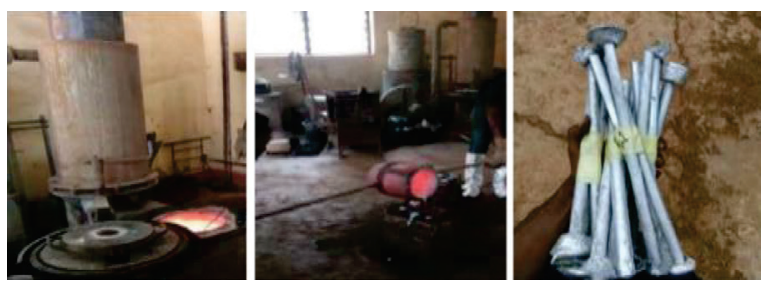

Fig. 2. The casting to the finished products

\subsection{The Alloy and Composites Tensile Strength}

A universal tensile testing machine was used to evaluate the tensile properties of the alloy/ composites produced. The test specimen preparation and testing procedure were in accordance with ASTM E8/E8M-15a [10] and shown in Fig. 3.

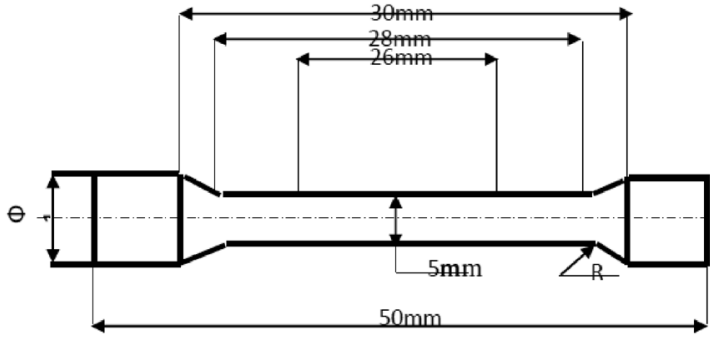

Fig. 3. Dimensions of tensile test specimen

\subsection{Hardness Values}

The sample preparation and testing procedure was performed in accordance with ASTM E18-16 [11]. The hardness values within the range of $2 \%$ were averaged to obtain the hardness value for the alloy and composites.

\subsection{Impact Toughness}

The impact specimen was placed on a horizontal stand of the Izod Impact Machine. It was arranged such that the notch was directly opposite to the point of impact of a heavily suspended mass. With the gauge set properly, the suspended mass was released from a height to hit the specimen. The energy absorbed by the specimen was reflected on a calibrated scale as reported by [12], and [13]. The results obtained were thus analysed.

\subsection{Microstructure of the Alloy/Composite}

Analysis of the microstructures of the alloy/composite was carried out using model JEOL 840 of scanning electron microscope attached with energy dispersive spectroscopy (SEM/EDS) after cutting, grinding, and polishing the specimens with different grades of papers in accordance with [14] and [15]. Etching was carried by wiping the specimen surface with wool soaked in natal to give a dull reflection surface [16].

\subsection{Wear Test}

The wear behaviour of the test samples (alloy and composites) was determined using the pin-on-disc test under dry conditions as stated for wear testing in [17]. It was carried out with the use of a Taber abrasion wear-testing machine. The wear test samples were produced in the form of a disc and machined to specifications $(200 \mathrm{~mm}$ diameter and 5 $\mathrm{mm}$ thickness). $10 \mathrm{~N}$ and $20 \mathrm{~N}$ loads were used, and the wear loss was evaluated according to [18]. 


\section{RESULTS}

\subsection{Mussel Powder Compositions}

The results revealed by the elemental analysis mussel shell powder from X-Ray Fluorescence (XRF) are presented in Table 1 and the powder particle size of $100 \mu \mathrm{m}$. From the table, the mussel shell powder contains calcium oxide content of $95.70 \%$, alumina of $0.46 \%$, silica of $0.83 \%$, magnesium oxide of 0.48 $\%$, aluminium oxide of $0.46 \%$, iron oxide of $0.67 \%$ and the remaining balance was lost on ignition (LOI) respectively.

\subsection{Microstructures}

The morphologies of the alloy and EDS are presented in Fig. 4, while the composites at various weight percent of the reinforcements from 0 wt. $\%$ to $15 \mathrm{wt}$. $\%$ of MSP was presented in Fig. 5.

\subsection{Mechanical Properties}

The results of the mechanical properties investigated such as hardness, tensile, impact toughness and percentage of elongation are also presented in Fig. 6 and Table 5, respectively.

\subsection{The Wear of the Alloy/Composites}

Figs. 7 and 8 presented the effect of reinforcement on specific wear rate and the morphologies of wear rate before and after the tests.

\section{DISCUSSION}

\subsection{Microstructure}

The performance of alloys or composite can be known through their microstructures. The alloys/ reinforcement with mussel powder examined were at $2000 \times$ magnification. The micrograph presented in Fig. 4 represents the aluminium alloy and its energy dispersive spectroscopy while Fig. 5 shows the composites produced with different percentage of MSP at 3 wt. \%, 6 wt. \%, 9 wt. \%, 12 wt. $\%$ and 15 wt. $\%$. From the figures, the calcium oxides $(\mathrm{CaO})$ distributed within the structures reveal fairly uniform distributions of MSP in the produced composite. There appears to be a reasonably uniform distribution of MSP in the alloy, which can be as a result of good interfacial bonding, decreases in particle size and increases in specific surface of the reinforcement for a given volume fraction [19]. The volume of $\mathrm{CaO}$ and $\mathrm{SiO}$ in MSP is shown in black while the white showed the matrix and conformed to the findings of [20].

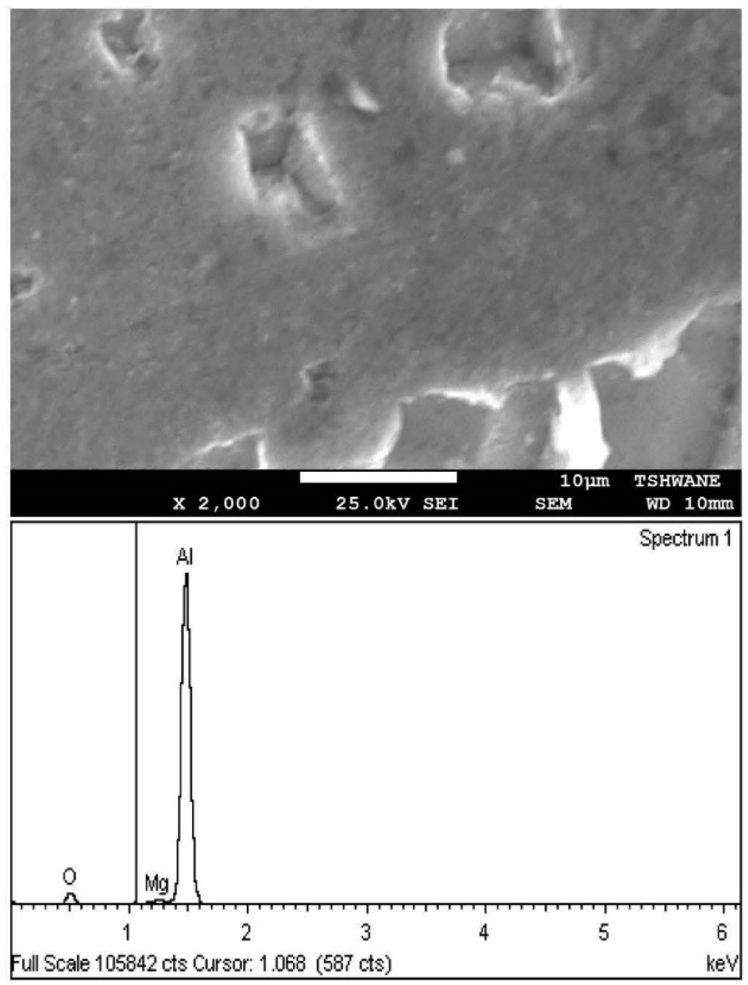

Fig. 4. SEM/EDS of aluminium alloy without reinforcement

Table 4. The EDS of the elements in Al-Mg-Si alloy

\begin{tabular}{lc}
\hline Element & Weight \% \\
\hline O K & 0.03 \\
\hline Cu K & 0.01 \\
\hline Mg K & 1.00 \\
\hline Al K & Balance \\
\hline Si K & 0.58 \\
\hline Cl K & 0.02 \\
\hline Fe K & 0.01 \\
\hline Ni K & 0.04 \\
\hline Mn K & 0.03 \\
\hline Totals & 100.00 \\
\hline
\end{tabular}

\subsection{Mechanical Properties of Alloy/Composites}

\subsubsection{Hardness Values}

The hardness, tensile strength, impact toughness and percentage elongation of the alloy and the composites were presented in Fig. 6 and Table 5. The hardness value of the alloy was $49.78 \mathrm{HRC}$ decreased to 13.16 HRC at 6 wt. \% of MSP and later increased to 53.52 

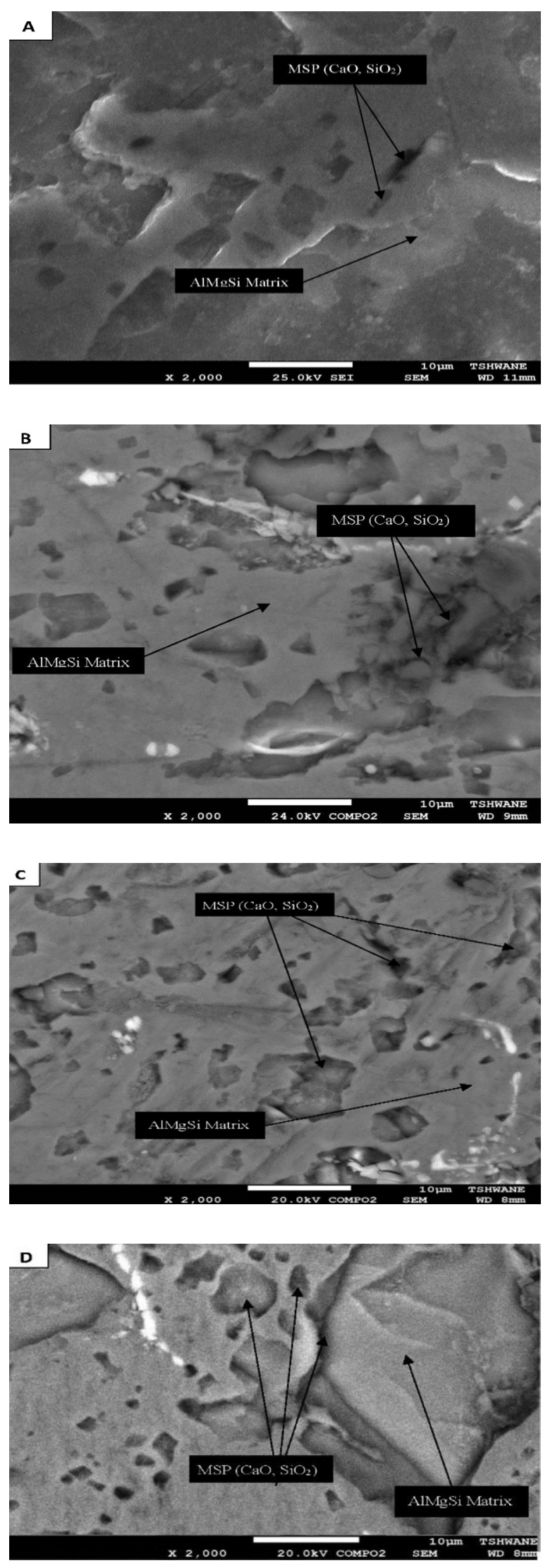

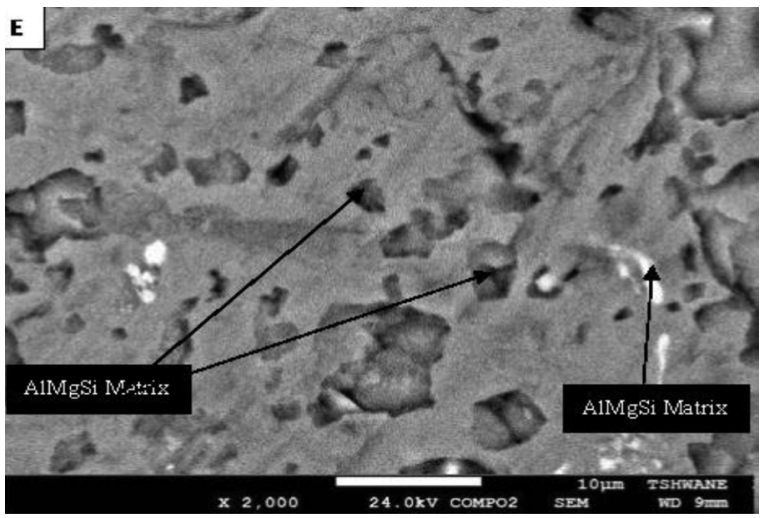

Fig. 5. SEM morphologies of aluminium alloy/composites at: a) 3 wt. \% MSP, b) 6 wt. \% MSP, c) 9 wt. \% MSP, d) 12 wt. \% MSP, and e) 15 wt. \% wt. \% MSP

HRC at 15 wt. \% MSP. That is a decrease of 73.56 $\%$ of the alloy to the composite at 6 wt. $\%$, and an increase of $75.41 \%$ at $15 \mathrm{wt}$ \% of MSP was recorded. Previous works attributed this increase in hardness to the decreased particle size and increased specific surface of the reinforcement for a given volume fraction [21]. The hardness values were improved at higher wt. \% of MSP loading. The improvement of the hardness of the composites to the increased particle volume fraction, and increased strain energy at the periphery of particles dispersed in the matrix confirmed the previous studies [22] and [23].

\subsubsection{Tensile Strength}

The alloy/composite with mussel powder results is shown in Fig. 6. The addition of mussel powder particles significantly improved the tensile strength of the composites compared to the alloy. The improvement observed in tensile strength of the composite was attributed to the fact that the mussel shell powder acts as filler and possesses higher strength which was more resistance [24]. The mussel shell contains ceramic materials, such as $\mathrm{CaO}, \mathrm{SiO}_{2}$, $\mathrm{Al}_{2} \mathrm{O}_{3}, \mathrm{Fe}_{2} \mathrm{O}_{3}$ which had a favourable combination of density; the hardness exhibits a significant increase in its elastic modulus, hardness, strength and wear resistance, accordingly [25]. Furthermore, the studies on Al-MMCs are mainly concentrated on Al-SiC, $\mathrm{Al}-\mathrm{Al}_{2} \mathrm{O}_{3}$ based systems with limited studies on $\mathrm{Al}-\mathrm{TiO}_{2}$ composites, though $\mathrm{TiO}_{2}$ particles have excellent mechanical properties [26] and [27]. Hence, improvement in the strength of the composites can be explained by the presence of ceramic particles in the mussel shell powder. It was therefore estimated that 
about $45 \%$ increase in the tensile strength from $0 \mathrm{wt}$. $\%$ to 3 wt. $\%$ MSP and $2.30 \%$ from 3 wt. $\%$ to 15 wt. $\%$ MSP, respectively.

\subsubsection{Elongation}

The percentage of elongation is shown in Fig. 6. It increases from 0 wt. $\%$ to 3 wt. $\%$ MSP and decreased from 3 wt. \% to 15 wt. \% MSP. However, at the particle size $(100 \mu \mathrm{m})$ of the filler due to high surface area and good wettability, the porosity of the composite decreases, which give rise to high strength at low percentage from 3 wt. $\%$ to 15 wt. $\%$ of the filler in the matrix [28].

\subsubsection{Impact Toughness}

The toughness results presented in Fig. 6 showed an increase from 0 wt. $\%$ to 3 wt. $\%$ and an decrease from 6 wt. $\%$ to 9 wt. $\%$ and an increase from $9 \mathrm{wt}$. $\%$ to 15 wt. $\%$ MSP. This sinusoidal change can be attributed to particle and interfacial cracking initially. The toughness values became virtually constant at 6 wt. $\%$ to 15 wt. \% MSP and similar to works of [29].

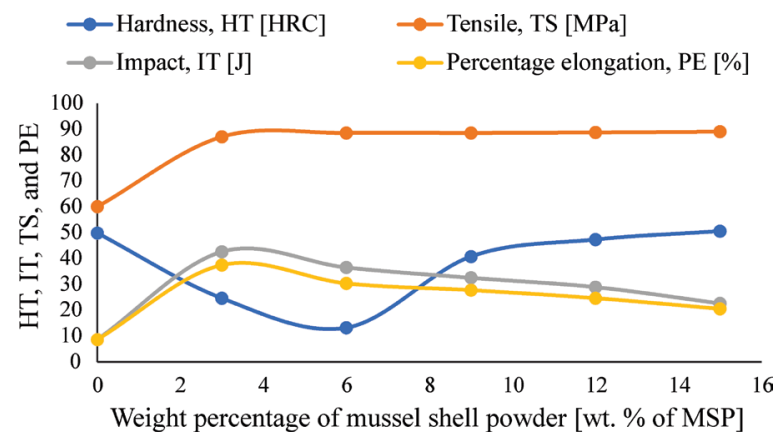

Fig. 6. Variations of hardness, tensile, impact and elongation of Alloy and composites against wt. \% MSP

Table 5. Values of the mechanical properties studied

\begin{tabular}{ccccc}
\hline $\begin{array}{c}\text { Wt. \% } \\
\text { MSP }\end{array}$ & $\begin{array}{c}\text { Hardness } \\
{[\mathrm{HRC}]}\end{array}$ & $\begin{array}{c}\text { Tensile } \\
\text { stress [MPa] }\end{array}$ & $\begin{array}{c}\text { Impact } \\
\text { test [J] }\end{array}$ & $\begin{array}{c}\text { Percentage } \\
\text { elongation [\%] }\end{array}$ \\
\hline 0 & 49.78 & 60 & 8.6 & 8.6 \\
\hline 3 & 24.58 & 87 & 42.6 & 37.4 \\
\hline 6 & 13.16 & 88.5 & 36.5 & 30.3 \\
\hline 9 & 40.7 & 88.5 & 32.5 & 27.7 \\
\hline 12 & 47.28 & 88.7 & 28.9 & 24.6 \\
\hline 15 & 50.52 & 89 & 22.6 & 20.5 \\
\hline
\end{tabular}

\subsubsection{Bending Test}

The bending test carried presented in Table 6 and Fig. 7. Bending results showed an increase from 0 wt. $\%$ to $15 \mathrm{wt}$. $\%$ of mussel shell powder and made of compressive and tensile stresses. This change can be attributed to particle and interfacial cracking which confirm the results of percentage elongation and impact results and similar to the previous works of [30], and, [31].

Table 6. Values of the Bending test at various reinforcements

\begin{tabular}{lc}
\hline wt. \% MSP & Stress [MPa] \\
\hline 0 & 119.5 \\
\hline 3 & 149.7 \\
\hline 6 & 150 \\
\hline 9 & 154.2 \\
\hline 12 & 160.3 \\
\hline
\end{tabular}

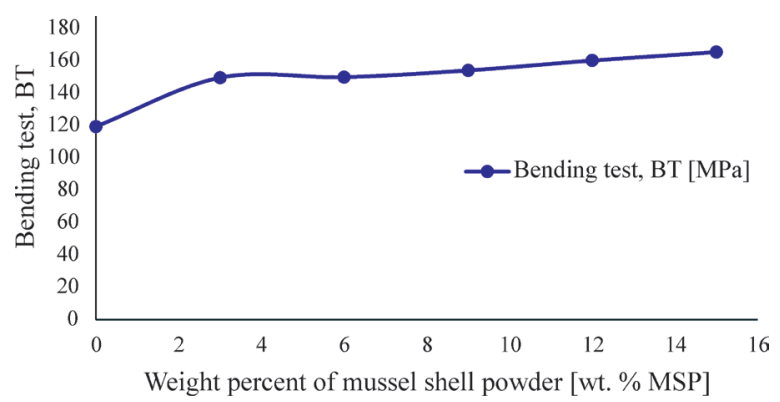

Fig. 7. Bending test of Aluminium alloy and composites against wt. \% MSP

\subsection{Wear Alloy/Composite Behaviours}

Wear is the gradual loss of material due to relative motion between a surface and the contacting substance and the wear damage may be in the form of microcracks or localized plastic deformation [32].

From Fig. 8, the wear rate of the composite decreases with increase in the wt. \% MSP reinforcement. Still in the figure, an increase in the applied load resulted in an increase in the wear rate of the samples investigated. The MSP beneficial effect on the wear resistance of the AlMgSi alloy composites is observed to be the best at low load and reduces with increase in applied load. Increases in MSP in the composite restricts deformation of the matrix material with respect to load; hence, the wear rate for the higher content of MSP composites decreases as seen in the figure and similar to work of [33]. The composites exhibited higher wear resistance at different applied loads. Wear rate at 9 wt. $\% \mathrm{MSP}$ are $30 \mathrm{~mm}^{3} /(\mathrm{Nm})$ and $47 \mathrm{~mm}^{3} /(\mathrm{Nm})$ at $10 \mathrm{~N}$ and $20 \mathrm{~N}$, respectively. This behaviour was attributed to the presence of MSP on the counter surface, which act as a transfer layer and 
effective barriers to prevent large scale fragmentation of the Al-Si-Mg matrix. Fig. 9 show the uniform distribution of MSP within the matrix before and after, supported with the low wear rate obtained. The wear rate increases with increase in applied load while it decreases with increase in the volume fraction of the reinforcement, as seen in Fig. 8 and supported the findings [34].

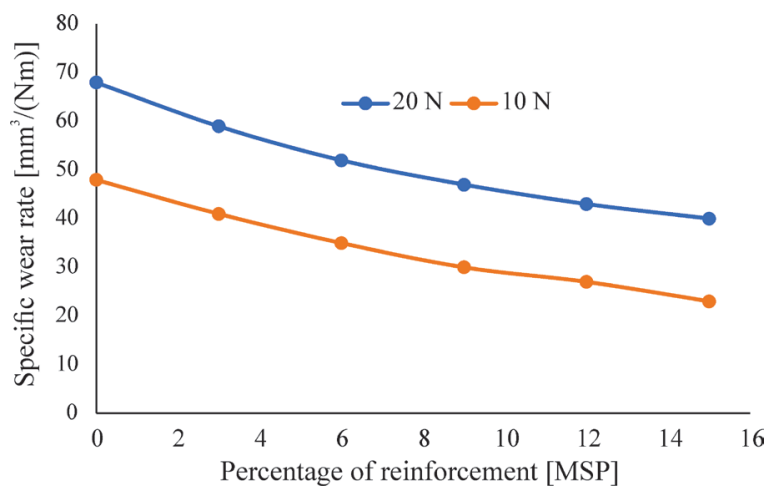

Fig. 8. Effect of reinforcement on specific wear rate
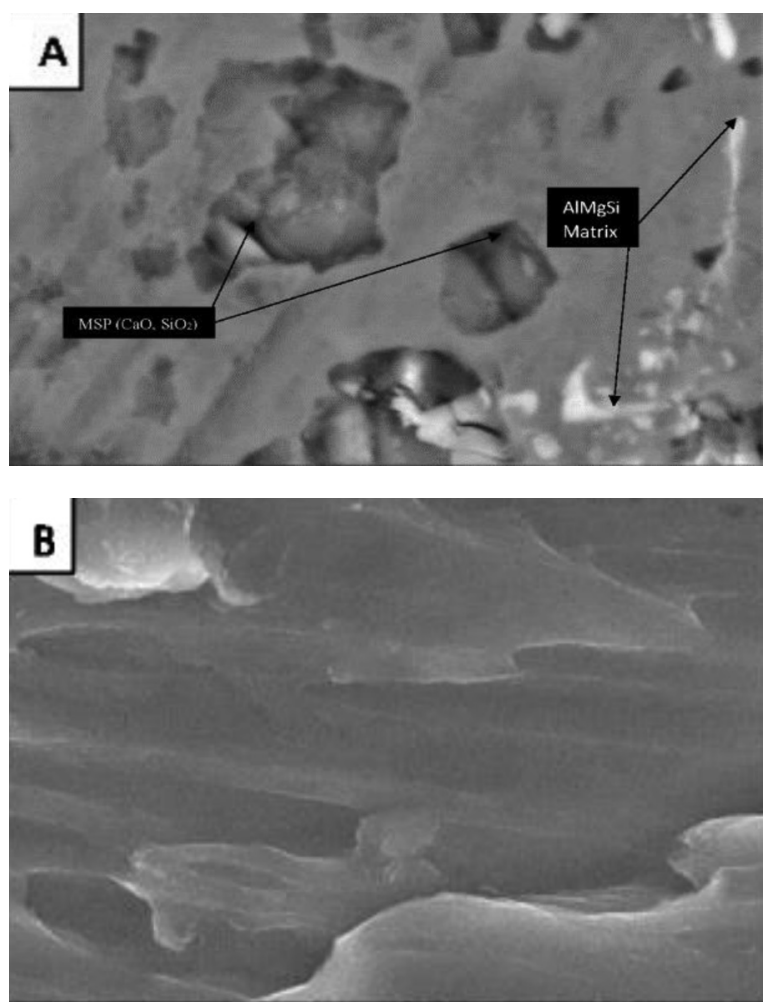

Fig. 9. Morphology of Aluminium alloy/ 6 wt. \% MSP a) before wear, and b) after wear

Fig. 10 shows the variation of the coefficient of friction with different applied loads. The coefficient of friction of both unreinforced Al-Mg-Si alloy and
Al-Mg-Si/MSP composites decreases as the applied load increase. The coefficient of friction increases as the amount of mussel shell powder particles reinforcement increases in the alloy. The amount of mussel shell powder particles was well-bonded with the matrix during sliding, the aluminium alloy matrix surrounding the particles were then worn away, which left the counter face and the reinforcing particles to be effectively in contact. If the particle has easy decohesion, contact occurred between the counter face and the matrix, and the hard particles cause a third body abrasion mechanism. It is then obvious that greater roughness and friction coefficient in the reinforced aluminium alloy (composites) than unreinforced aluminium alloy and also confirmed the previous works [34] and [35].

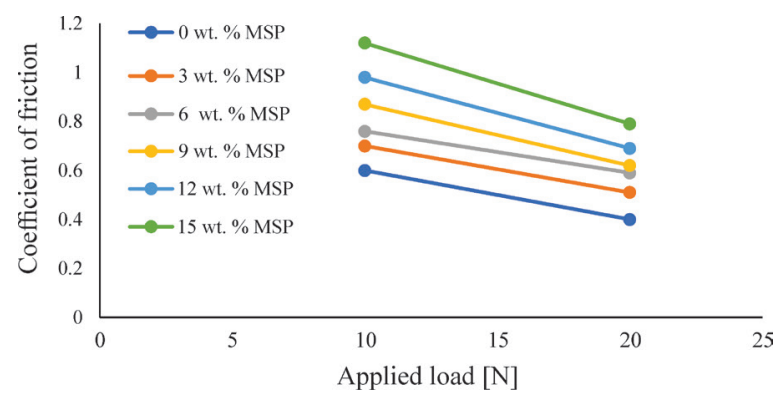

Fig. 10. Variations of coefficient of friction with applied load

\section{CONCLUSIONS}

The purpose of this work was to investigates the use of aquaculture MSP of particle size $100 \mu \mathrm{m}$ by dispersing it into aluminium metal composites via liquid metallurgy to obtain composites for mechanical, microstructure and wear properties analyses. Therefore, the following conclusion have been drawn from the results:

1. The mussel shell powder is a potential reinforcer that had improved mechanical and wear rate behaviours investigated.

2. Hardness value decreases with increase in wt. \% mussel shell powder and later increase as the wt. $\%$ of MSP was increased because of the higher particle size of MSP. The tensile strength, impact toughness, and elongation were also enhanced positively at different composition of MSP.

3. Microstructures clearly revealed that the composites materials produced by stir casting method showed no voids and discontinuities of MSP particulates in the matrix which resulted in sound castings. 
4. The wear resistance of the composites increases with increase in the applied load and decrease with increase in the weight percentage of MSP.

5. The morphologies of the wear rate of the composite revealed that the material removal was mainly due to micro-cutting and as such, MSP was a good substitute for the imported material, in addition to being easily available, cheap, and environmentally friendly.

\section{ACKNOWLEDGEMENTS}

The authors are thankful to the staff of Department of Metallurgical and Materials Engineering, University of Nigeria, Nsukka and Department of Chemical, Metallurgical and Materials Engineering, Tshwane University of Technology, Pretoria, South Africa, Main Campus Pretoria West

\section{REFERENCES}

[1] Chak, V., Chattopadhyay, H., Dora, T.L. (2020). A review on fabrication methods, reinforcements and mechanical properties of aluminum matrix composites. Journal of Manufacturing Processes, vol. 56 p. 1059-1074. DOI:10.1016/.j.jmapro.2020.05.042.

[2] Arunachalam, R., Krishnan, .PK., Muraliraja, R. (2019). A review on the production of metal matrix composites through stir casting-Furnace design, properties, challenges, and research opportunities. Journal of Manufacturing Process, vol. 42, p. 213-245, D0I:10.1016/j.jmapro.2019.04.017.

[3] Kala, H., Mer, K.K.S., Kumar, S. (2014). A review on mechanical and tribological behaviors of stir cast aluminum matrix composites. Procedia Materials Science, vol. 6, p. 1951-1960, Dol:10.1016/j.mspro.2014.07.229.

[4] Ofem, M.l., Umar, M., (2012). Effect of filler content on the mechanical properties of periwikle shell reinforced cnsl resin composites. ARPN Journal of Engineering and Applied Sciences, vol. 7, p. 212-215.

[5] Alaneme, K.K., Adewale, T.M., Olubambi, P.A. (2014). Corrosion and wear behaviour of Al-Mg-Si alloy matrix hybrid composites reinforced with rice husk ash and silicon carbide. Journal of Materials Research Technology, vol. 3, no. 1, p. 9-16, D0I:10.1016/J.jmrt.2013.10.008.

[6] Agunsoye, J.0., Talabi, S.I., Bello, S.A., Awe, I.O. (2014). The effects of cocos nucifera (coconut shell) on the mechanical and tribological properties of recycled waste aluminium can composites. Tribology in Industry, vol. 36, no. 2, p. 155-162.

[7] Kok, M. (2005.) Production and mechanical properties of Al203 particle-reinforced 2024 aluminium alloy composites. Journal of Materials Process and Technology, vol. 161, no. 3, p. 381-387, D0I:10.1016/J.jmatprotec.2004.07.068.

[8] Usman, A.M., Raji A., Hassan, M.A., Waziri, N.H., (2014). A comparative study on the properties of Al-7\%Si-rice husk ash and Al-7\%Si-bagasse ash composites produced by stir casting.
International of Journal of Engineering Sciences, vol. 3, no. 8, p. 1-7.

[9] Umunakwe, R., Olaleye, D.J., Oyetunji, A., Okoye, O.C., Umunakwe, I.J. (2017). Assessment of the density and mechanical properties of particulate periwinkle shellaluminium 6063 metal matrix composites (PPS-ALMMC) produced by two-step casting. Nigerian Journal of Technology, vol. 36, no. 2, p. 421-427, D0I:10.4314/njt.v36i2.14.

[10] ASTM E8 / E8M-15a (2015). Standard Test Methods for Tension Testing of Metallic Materials, ASTM International, West Conshohocken.

[11] ASTM E18-16 (2016). Standard Test Methods for Rockwell Hardness of Metallic Materials, ASTM International, West Conshohocken.

[12] Nandakumar, N., (2018). Experimental Investigation on Mechanical Properties of Al6061 Hybrid Metal Matrix Composite Reinforced with Silicon Carbide and Graphite. International Journal of Computer Sciences and Engineering, vol 6, no. 5, p 397-402, Dol:10.26438/ijcse/v6i5.397402.

[13] Pandey, U., Purohit, R., Agarwal, P., Dhakad, S.K., Rana, R.S. (2017). Effect of TiC particles on the mechanical properties of aluminium alloy metal matrix composites (MMCs). Materials Today: Proceedings, vol. 4, no. 4, p 5452-5460, D0I:10.1016/j.matpr.2017.05.057.

[14] Niranjan, K.N., Shivaraj, B.N., Sunil Kumar, M., Deepak, A.R. (2017). Study of mechanical properties on Al 6061 hybrid composites by stir casting method. International Research Journal of Engineering and Technology, vol. 4, no. 1, p. 10361040.

[15] Suleiman, I.Y., Sani, A.S., Mohammed, T.A., (2018). Investigation of mechanical, microstructure, and wear behaviors of $\mathrm{Al}-12 \% \mathrm{Si} /$ reinforced with melon shell ash particulates. The International Journal of Advanced Manufacturing Technology, vol. 97, p. 4137-4144, DOI:10.1007/s00170-018-2157-9.

[16] Dieter, G.E. (1998). Mechanical Metallurgy. McGraw-Hill, New york.

[17] Meena, K.L., Manna, A., Banwait, S.S,, Jaswanti. (2013). An analysis of mechanical properties of the developed Al/SiCMMC's. American Journal of Mechanical Engineering, vol. 1, no. 1, p. 14-19, Dol:10.12691/ajme-1-1-3.

[18] Apasi, A., Yawas, D.S., Abdulkareem, S., Kolawole, M.Y. (2016). Improving mechanical properties of aluminium alloy through addition of coconut shell-ash. Journal of Science Technology, vol. 36, no. 3, p. 34-43.

[19] Deuis, R.L., Subramanian, C., Yellup, J.M., (1996). Abrasive wear of aluminium composites-a review. Wear, vol. 201, no. 1-2, p. 132-144, Dol:10.1016/S0043-1648(96)07228-6.

[20] Thakur, S.K., Dhindaw, B.K. (2001). The influence of interfacial characteristics between SiCp and $\mathrm{Mg} / \mathrm{Al}$ metal matrix on wear, coefficient of friction and microhardness. Wear, vol. 247, no. 2, p. 191-201, DOI:10.1016/s0043-1648(00)00536-6.

[21] Mahmoud, T. S. (2008). Tribological behaviour of A390/Grp metal matrix composites fabricated using a combination of rheocasting and squeeze casting techniques. Proceedings of the Institution of Mechanical Engineers, Part C: Journal of Mechanical Engineering Science, vol. 222, no. 2, p. 257-265. DOI:10.1243/09544062JMES468. 
[22] Sozhamannan, G.G., Balasivanandha Prabu, S., Venkatagalapathy, V.S.K. (2012). Effect of processing paramters on metal matrix composites: Stir casting process. Journal of Surface Engineered Materials and Advanced Technology, vol. 2, no. 1, p. 11-15, Dol:10.4236/ jsemat.2012.21002.

[23] Gomes, J.R., Ramalho, A., Gaspar, M.C., Carvalho, S.F. (2005). Reciprocating wear tests of Al-Si/SiCp composites: A study of the effect of stroke length. Wear, vol. 259, no. 1-6, p. 545552, D0I:10.1016/j.wear.2005.02.088.

[24] Howell, G.J., Ball, A. (1995). Dry sliding wear of particulatereinforced aluminium alloys against automobile friction materials. Wear, vol. 181-183, p. 379-390, D0l:10.1016/00431648(95)90045-4.

[25] Vencl, A., Bobić, I., Mišković, Z., (2008). Effect of thixocasting and heat treatment on the tribological properties of hypoeutectic Al-Si alloy. Wear, vol. 264, no. 7-8, p. 616-623, D0l:10.1016/j.wear.2007.05.011.

[26] Gireesh, Ch.H., Durga Prasad,.K.G., Ramji, K., Vinay, P.V. (2018). Mechanical characterization of aluminium metal matrix composite reinforced with aloe vera powder. Materials Today: Procedings, vol. 5, no. 2, p. 3289-3297, D0l:10.1016/j. matpr.2017.11.571.

[27] Sharma, V.K., Singh, R.C., Chaudhary, R. (2017). Effect of fly ash particles with aluminium melt on the wear of aluminium metal matrix composites. Engineering Science and Technology, an International Journal, vol. 20, no. 4, p. 13181323, D0l:10.1016/J.jestch.2017.08.004.

[28] Nirmal, U-, Hashim, J., Megat Ahmad, M.M.H. (2015). A review on tribological performance of natural fiber polymeric composites. Tribology International, vol. 83, p. 77-104. D0l:10.1016/j.triboint.2014.11.003.

[29] Chauhan, H., Irfan, Chauhan, A. (2017). Variation of mechanical properties (tensile strength $\mathrm{h} \&$ microstructure) of
Al6061 / ( $\mathrm{Al}_{2} \mathrm{O}_{3}$ and fly ash), hybrid metal matrix composite produced by stir casting. International Research Journal of Engineering and Technology, vol. 4, no. 7, p. 2407-2414.

[30] Tugiman, Ariani, F., Taher, F., Hasibuan, M.S., Suprianto (2017). The analysis of composite properties reinforced with particles from palm oil industry waste produced by casting methods. IOP Conference Series: Materials Science and Engineering, vol. 277, art. ID 012028, D0I:10.1088/1757899X/277/1/012028.

[31] Francis Xavier, L., Paramasivam, S. (2016). Wear behavior of aluminium metal matrix composite prepared from industrial waste. The Scientific World Journal, vol. 2016, art. ID 6538345, D0l:10.1155/2016/6538345.

[32] Abdulwahab, M., Dodo, R.M., Suleiman, I.Y., Gebi, A.I., Umar, I. (2017). Wear Behavior of Al-7\%Si-0.3\%Mg/melon shell ash particulate composites. Heliyon, vol. 3, no. 8, art. ID e00375, DOI:10.1016/j.heliyon.2017.e00375.

[33] Phanibhushana, M.V., Chandrappa, C.N., Niranjan, H.B. (2017). Study of wear characteristics of hematite reinforced aluminum metal matrix composites. Materials Today: Proceedings, vol. 4, no. 2, p. 3484-3493, D0l:10.1016/j. matpr.2017.02.238.

[34] Chandla, N.K., Yashpal, K., Jawalkar, C.S., Suri, N.M. (2017). Review on analysis of stir casting aluminium metal matrix composites from agro-industrial waste. i-Manager's Journal of Materials Science, vol. 5, no. 2, p. 35-46, D0l:10.26634/ jms.5.2.13658.

[35] Lancaster, L., Lung, M.H., Sujan, D. (2013). Utilization of agro-industrial waste in metal matrix composites: Towards sustainability. International Journal of Environmental, Ecological, Geomatics, Earth Science and Engineering, vol. 7, no. 1, p. 35-43, HDL:20.500.11937/37923. 